\title{
A Brief Analysis on the Stylistic Features of English for Business Contracts
}

\author{
Jiang Zhu \\ School of Foreign Languages, Changchun University of Science and Technology, Changchun, China \\ Email: zhujiang98@163.com \\ Qian Wu \\ School of Foreign Languages, Changchun University of Science and Technology, Changchun, China \\ Email: sissixinxiang@sina.com
}

\begin{abstract}
English for business contract is a sub-variety of legal English. This paper aims to investigate the stylistic features of English for business contracts. First, it introduces the definition, development and basic contents of style, stylistics and contract's style. Then it analyzes the specific stylistic features of English for business contracts from perspectives of lexicon. The paper also analyzes the stylistic features in terms of syntax.
\end{abstract}

Index Terms - English for business contracts, stylistic features, lexical features, syntactic features

Nowadays the research on the styles of the varieties of English becomes very popular. English for business contract, a sub-variety of legal English, has its distinctive stylistic features. This paper will analyze the features in detail.

\section{The Introduction of Style, Stylistics And CONTRACT'S STYLE}

To carry out a stylistic analysis of English for business contracts, it is necessary to know what style and stylistics are.

Wang Zuoliang and Ding Wangdao (1987) explain that: "In a narrow sense, style refers to literary style, including author's writing style; in a broad sense, style refers to style of all kinds in language" (p.25). Generally speaking, the style of the contract in the study of this paper belongs to one in a broad sense. According to Longman Dictionary of Applied Linguistics (2002), style is the manner of expression in writing or speaking which changes at all times according to the actual situational elements, e.g. the participants, time, place, topic, etc. of the communicative event, from very formal to very informal. According to modern stylistics, style can be defined as the language use habits of a person or a group of people in a given situation. As different situations tend to yield different varieties of a language that in return display different linguistic features, style may be seen as the various characteristics of language use in various contexts.

Stylistics, which is the systematic and scientific study of style, is helpful to acquire the ability of using language appropriately. Widdowson (1979) defines that "by stylistics, I mean the study of literary discourse from a linguistic orientation and I shall take the view that what distinguishes stylistics from literary criticism on the one hand and linguistics on the other is that it is essentially a means of linking the two"(p.67). According to Qian Yuan (1990), stylistics is the study of style. It is a branch of linguistics in which the theories and methodologies of modern linguistics are applied to the study of the styles of the varieties of language appeared in language use. Compared with other definitions, this definition is complete and precise.

From the angle of the function of the language in use, Chen Xin (1999) divides style into applied style, news style, advertisement style, science and technology style and literature style. In this way, contract English falls within the scope of applied style. Judging from various degrees of formality, he classifies the extent of formality into five levels in his work The Five Clocks, that is: frozen, formal, consultative, casual, and intimate. Generally speaking, frozen style is used publicly for some serious purposes in professional documents, such as legal statements and regulations, official reports, scientific papers, etc. Archaic words, Latin words, compound adverbs, noun phrases, complete sentences, long sentences, complicated sentence structures, clear logical relationships between sentences, serious tone, passive voice and strictness with grammatical rules are often held as the marks of frozen English. English for business contracts perfectly suits those traits and sequentially pertains to the frozen style.

The contract, being an applied style, falls within the ambit of legal documents. Apart from the contract, legal documents usually include statutes, decrees, legal provisions, insurance policies, etc. Yet, all the legal documents have the same function: imposing obligations and conferring of rights. Legal English, in this way, concerns with the guarantee of people's rights, and the enforcement of their obligations. To ensure that a legal document says exactly what it is meant to say, and leaves no chance for misinterpretation, the draftsman of the legal document has to pay special attention to the precision of wording, and avoidance of misunderstanding and ambiguity. Accordingly, legal English appears extremely conservative and presents some striking oddities in form and wording, and so does English for 
business contracts. English for business contracts, as a variety of legal English, just bears the general traits of legal English, and is most often presented in the written form. To tell the fact and express the meeting of minds of the parties in an extremely precise way, the draftsman of the contract is reliant on established forms and tends to employ tested modes of expressions.

\section{Stylistic Features of ENGLish fOR Business CONTRACTS}

In the following part, I will analyze the stylistic features of English for business contracts in two aspects: lexical features and syntactic features.

\section{A. The Lexical Features of English for Business Contracts}

\section{Formal words}

Formal language indicates that it is a special occasion, quite different from ordinary discourse. Formal language is one of the traits of the contract lexicon. Compared with general English, English for business contracts is very formal. A lot of formal words, which are rarely used in general English, are used in English for business contracts. Here we list just a small sampling:

\begin{tabular}{|l|l|}
\hline Formal Words & Common Words \\
\hline approximately & around \\
\hline commence/initiate & begin/start \\
\hline construe & explain \\
\hline convene & call \\
\hline employ & use \\
\hline notify & tell \\
\hline present & give \\
\hline execute & sign \\
\hline terminate & end \\
\hline
\end{tabular}

Formal words are also frequently employed in English for business contracts. Generally speaking, most of them originate from Latin, French or other languages. The function of these words is to increase precision and avoid ambiguity in business contracts and increase the seriousness of the content. English for business contract makes direct and clear specifications for exact meaning and the wording must be formal and does not bring individual emotional hint.

2. Archaic words

A distinctive feature of English for business contracts is the use of archaic words, which are employed frequently in legal documents but not commonly used in other varieties. These words often appear in the form of compound adverbs. They are formed by adverbs "here, there, where" combining with some particles as "after, at, by, from, in, of, to, under, upon, with, as, etc". e.g., hereto, herein, hereby, hereof, whereby, thereafter, etc. "Here", "there" and "where" in these compounds mean "this", "that" and "what or which" respectively. For example,

Hereto... to this...

Thereby...by that...

Whereof...of which...

The use of archaic words helps maintain the formality of English for business contracts as well as the exactness of the content and avoid misinterpretation or ambiguity. Archaic words make the texts rather concise and accurate. At the same time, they make the contracts difficult to comprehend because they are rarely used in our daily life. The frequent use of archaic words renders the texts rather formal and forms a distinctive feature of English for business contracts.

3. Loan words

In English for business contracts, loanwords, especially those that are of Latin or French origin are frequently employed. Latin words were gradually pervaded into English along with the introduction of Christian; while French was borrowed to enrich English for the historical reason of the Norman Conquest in the year of 1066. Those loanwords are conserved in legal English for their preciseness and mono-meaning. Hence they are also readily found in English for business contracts.

The "force majeure clause" belongs to general provision that is widely used in business. Let's have a look of the following sentence:

In case of force majeure, such as war, serious fire, flood, typhoon and earthquake or other events of force majeure, the seller shall not be held responsible for delay in delivery or non-delivery of the contracted goods.

In this sentence, the term "force majeure" is a legalese from French which means insuperable force or an event or effect that cannot be reasonably anticipated or controlled. In English for business contracts, a large number of legal terms are preserved which are of Latin or French origin. Loanwords are of stabilized meanings, which are conducive to accurate expression of the legal concepts.

4. Technical Terms

A contract is a legal document which is signed and obeyed by both parties. Therefore the language of contracts should embody definitiveness and exactness. One characteristic of English for business contracts is shown by using technical terms. For example: 
Within the validity period of contract, license shall not disclose or divulge know-how to any third party without prior written consent of licensor.

In the above sentence, "know-how" has such an exact meaning as to demonstrate the technical information, design, production procedures and other information of product with license.

In order to describe exactly both parties' rights and obligations in business exchange, many legal terms are used in business contracts. For example:

In processing transactions, the manufacturers never have title either to the materials or to the finished products.

According to American Heritage Student's Dictionary (2000), "title" in the above sentence means the legal right or claim to ownership or possession. So "title" shall be regarded as a legal terms rather than an ordinary word.

5. Coordination of Synonyms

In legal English, two synonyms can be used together. this usage occurs frequently. It is especially an outstanding characteristic of contracts, for by using it, ambiguity can be avoided or reduced. Look at the following sentences:

They declared the contract null and void.

The packing and wrapping expenses shall be borne by the buyer.

The purpose of this usage is not only to respect the tradition, but also to seek accuracy and completeness of meaning. Legal English adheres much to tradition, which is mentioned by many linguists. There are many such synonymous pairs: terms and conditions, settle claims and debts, import duty and tax, customs and usages, missing and disappeared person, willful and malicious injury, elderly and aged, etc. The synonyms and near-synonyms in each phrase are usually connected and the second part is often used to reaffirm and complement the first part.

Sometimes, draftsmen may use some combinations of synonyms to make the meaning more rigorous, accurate and complete. For example, alteration, modification or substitution; defaced or altered; loss, injury, or damage; use, misuse, or abuse; in contract or in tort; expressed or implied; altered or amended; repair or replacement. Among them, loss, injury, or damage; in contract or in tort; expressed or implied are frequently used formulas. Some words, which are not synonyms or near-synonyms, are also used together for accuracy, for instance: breaking and entering, shall be or remain liable, etc. It is blameless to use commonly used reduplications of synonyms or near-synonyms to obey the habit of legal English, while it is necessary to avoid using superfluous words.

\section{B. Syntactic Features of English for Business Contracts}

English business contracts should be objective and show no personal emotions. Thus it has some distinctive syntactic features.

\section{Long sentences}

Compared with general English, the sentence structure of English for business contracts is more complicated and perplex. In a contract, usually "a huge amount of information has been compressed into a single sentence, which accounts for its length and grammatical complexity". Long sentences are frequently utilized in business contracts to include the rights and obligations of the contracting parties in a limited space of the clauses comprehensively and sufficiently. Unlike other style of language, especially informal conversation, which prefers to convey connected information in a series of short or broken sentences, contract English tends to put all such sequences into the form of very complex sentences capable of standing alone, by means of an array of subordinating devices. Some clauses of a contract are composed of just one very long sentence. Even in the clause that is composed of several sentences, the sentences tend to be extremely long. The utilization of long sentence in the contract is inevitable and necessary for enabling the preciseness of sentence structure and the accuracy and comprehensiveness of meanings. But for the long sentences and the many modifiers therein, it would not be so difficult for laymen to understand the meanings of the contractual clause. For example:

The undersigned representative hereby declares and agrees that, if and when the tender is awarded and after the formal contract is signed and, therefore, the performance bond is established, the buyer is kindly requested to advance five percent $(5 \%)$ of the contract value as commencement support for the supply of water and electricity and erection of temporary facilities, and the advance thereof shall be deducted from the subsequent monthly progress payments.

The average length of English sentence is 17 words, but the above-illustrated sentence consists of 71 words, where the verbs "declares and agrees" are followed up with an object clause made up of three adverbial clauses to indicate time, condition and mode of payment respectively.

Another example:

In case that one or both parties are impossible to perform the duties provided herein on account of force majeure, the party (or parties) in contingency shall inform the other party (or each other) of the case immediately and may, provided the case is duly verified by the competent authorities, delay in performance of or not perform the relevant duties hereunder and may be partially or entirely exempted from the liability for breach of this agreement.

The 76-word sentence in the above example consists of an adverbial clause, a completed predicate in the main clause and a prepositional phrase acting as causal adverbial. Besides, the second predicate of the main clause consists of a conditional adverbial clause.

All in all, the predominance of long sentences is one distinctive feature of English for business contracts.

2. Proper application of passive voice 
Passive voice is frequently used in contracts mainly to emphasize the action but not the doer, and give predominance to the fact but not individual feeling and personal will. In consideration of the stylistic factors and function, passive voice, which makes the statement more formal and objective, is used much more extensively and frequently in English for business contracts than in many other varieties of English. Passive voice sentences are always predominant in the provisions of packing, shipping, insurance, disputes resolution, payment and arbitration, etc. Take the following as examples:

The contract is written in Chinese and English, with both versions having the same legal force.

When amendment is made to this contract and its appendixes, it shall not be valid unless a written agreement is signed by both parties and submitted to and approved by the original inspection authorities.

After the contract expires and the lessee returns the leased premises, the deposit (without interest) shall be refunded only when it has been determined that the lessee has complied with all of the articles and obligations stipulated in this contract.

In these sentences, the passive voice is used to construct a wordier sentence and disrupt the ordinary sequence of events in the reader's mind as a given hint that the focus here is different, i.e. it emphasizes the action but not the doer. Just as Garner (1991) observes that the English-speaking reader generally expects a normal sequence of sentence, that is, subject, verb, and object, as opposed to an inverted sequence, unless the inversion somehow improves the statement. Overall, passive voice is frequently adopted in English for business contracts because of the necessity in the contract to emphasize the objectivity and the nature of preciseness.

\section{CONCLUSION}

English for business contracts is playing a leading role in all the business activities. English for business contracts, a sub-variety of legal English, takes up a large proportion of the languages used in business contracts. Many English contracts work as a legal document and weapon for enhancing the development and being on guard for payment risk. Thus it is worth studying for its specific features.

\section{REFERENCES}

[1] Chen Xin. (1999). A Guide to English-Chinese Translation of Stylistic Varieties. Beijing: Peking University Press.

[2] Dong Qiming. (2008). English Stylistics: A New Course Book. Beijing: Foreign Language Teaching and Research Press.

[3] Garner, B.A. (1991). The Elements of Legal Style. Oxford: Oxford University Press.

[4] Qian Yuan. (1990). Stylistics: A Coursebook for Chinese EFL Students. Beijing: Beijing Normal University Press.

[5] Tiersma, P. M. (1999). Legal Language. Chicago: The University of Chicago Press.

[6] Widdowson, H.G. (1979). Explorations in Applied Linguistics. Oxford: Oxford University Press.

[7] Wang Zuoliang \& Ding Wangdao. (1987). Introduction to English Stylistics. Beijing: Foreign Language Teaching and Research Press.

[8] Weng Fengxiang. (2007). Translation for Contemporary International Business English. Shanghai: Shanghai Jiao Tong University Press.

Jiang Zhu was born in Changchun, China in 1971. He received his M.A. degree in linguistics from Changchun University of Science and Technology, China in 2003.

$\mathrm{He}$ is currently an associate professor in School of Foreign Languages, Changchun University of Science and Technology. His research field is English stylistics and applied linguistics.

Qian Wu was born in Songyuan, China in 1987. She received her B.A. degree in English from Changchun University of Science and Technology, China in 2010.

She is now studying to get her M.A. degree in linguistics in School of Foreign Languages, Changchun University of Science and Technology. Her research field is English stylistics and applied linguistics. 